\title{
Introducing the Internet
}

\author{
Mark Pallen
}

\section{Internet}

This is the first in a short series introducing the Internet to medical practitioners
The benefits to medical practitioners of using the Internet are growing rapidly as the Internet becomes easier to use and ever more biomedical resources become available on line. The Internet is the largest computer network in the world; it is also a virtual community, larger than many nation states, with its own rules of behaviour or "netiquette." There are several types of Internet connection and various ways of acquiring a connection. Once connected, you can obtain, free of charge, programs that allow easy use of the Internet's resources and help on how to use these resources; you can access many of these resources through the hypertext references in the on line version of this series (go to http://www.bmj.com/ bmj/ to reach the electronic version). You can then explore the various methods for accessing, manipulating, or disseminating data on the Internet, such as electronic mail, telnet, file transfer protocol, and the world wide web. Results from a search of the world wide web for information on the rare condition of Recklinghausen's neurofibromatosis illustrate the breadth of medical information available on the Internet.

Imagine a working environment where, without moving from your desk in, say, London, you could:

- Consult colleagues worldwide on a clinical problem at the click of a mouse ${ }^{1}$

- Send a draft of a paper to coauthors half a world away and receive their amended versions of the paper later the same day

- Read dozens of journals without paying a single subscription charge ${ }^{23}$

- Brush up on your continuing medical education by, say, studying magnetic resonance imaging in Florida ${ }^{4}$

- Retrieve a DNA sequence file the day that it is published $^{5}$

- Hold real time discussions with researchers from North America, the Middle East, and continental Europe

- Browse through a bookshop's catalogue, then order and pay for your favourite textbook.?

Such an environment already exists-it is called the Internet. For some, the Internet is a place of hope and unbounded potential ${ }^{89}$; for others it is a seductive waste of time. ${ }^{10}$ Many doctors see the Internet as unfamiliar territory, with strange customs $\mathrm{s}^{11}$ and impenetrable jargon. However, for all medical practitioners, whatever their specialty, the benefits of using the Internet are growing rapidly, just as costs and learning times are plummeting. ${ }^{12-14}$

The increasing benefits arise from an ever larger biomedical presence on the net, including an explosion of new biomedical sites and resources. The Internet is already an essential tool in much medical research (particularly in molecular biology). It is likely soon to become an important resource for teaching medical students, for clinical practice, and for postgraduate and continuing medical education. ${ }^{15-18}$ The Internet may eventually become the preferred medium for the publication of research in medicine (as it is already for high energy physics)..$^{19}$

The Internet has become much easier to use in the last few years. Until recently, the newcomer to the net (the "newbie") had to master the arcane intricacies of UNIX, a powerful but unfriendly operating system. Nowadays, to connect to and use the Internet, the average person need know almost nothing about how it works and where it came from. Within minutes of first connecting, you can be "surfing the net" just by clicking on your mouse button.

The Internet has also become a much richer and a more interesting place. Where once accessing the Internet meant peering myopically at text on a monochrome monitor, it now means feasting on a banquet of colours, sounds, and movies, with virtual reality and video on demand soon to follow.

\section{What is the Internet?}

The Internet is the largest computer network in the world. Just like any other computer network, it consists of a set of computers, a set of physical (or wireless) links between the computers, and a set of rules or protocols governing the exchange of information between computers.

One of the strengths of the Internet is that almost any type of computer can connect to it, ranging from powerful mainframes to humble microcomputers (such as the Apple Macintosh, IBM PC, Commodore Amiga, and Acorn Archimedes). These computers are linked in several ways: by traditional twisted copper phone lines, ISDN (integrated services digital network) lines, optical fibres, and even satellite links. All computers on the Internet, by definition, exchange information through the same set of protocols (TCP/IP: transmission control protocol/internet protocol). Most computers on the Internet are also part of smaller networks that serve, say, universities or companies.

Assessing the size of the Internet is difficult. According to one recent estimate, 4852000 computers were connected to the Internet in January 1995-and this figure had more than doubled in the previous year. ${ }^{20}$ The number of these computers serving just one component of the Internet, the world wide web, had grown more than 30 -fold over the same time. ${ }^{21}$

The Internet is not, however, just a large computer network-it is also a vast community, larger than many nation states, that provides intellectual, psychological, and social support for its inhabitants. ${ }^{8}$ Recently the Matrix Information and Directory Services estimated that 13.5 million people were within the core Internet in October 1994, with an additional 14 million people in the Internet's hinterland-the larger cluster of networks (sometimes called the "matrix") that can exchange limited information, such as electronic mail, with the Internet proper. ${ }^{22}$

The Internet as a community has its own rules and customs, often quite unlike those outside "in real life" (known, following the Internet's fondness for acronyms, as "IRL"). You will often find a remarkable civility and willingness to help that may restore your faith in humanity and in the collaborative spirit of 
medicine and science; occasionally, however, you may also meet extreme discourtesy or vulgarity.

\section{Connecting to the Internet}

There are at least three levels of Internet access. The most basic is through electronic mail from a machine that is outside the Internet but still in the matrix. This gives you access to most Internet services, albeit in a rather clumsy manner. This may be the only option in developing countries or in eastern Europe.

The next most basic connection is through a "shell account." Here you establish a real time interactive connection between your computer and another machine that is permanently connected to the Internet (and which usually runs UNIX). Your computer does not become part of the Internet proper, but you can use the connection to gain text only access to most Internet services.

To gain full Internet access you need software to handle the TCP/IP protocols. The type of software depends on the operating system you use. Installing this software is usually straightforward; your local computer service may even do it for you. In the United Kingdom, most academic institutions are connected to the Joint Academic Network (JANET) and its Internet service (JIPS), so staff and students can access the Internet free of charge (at least through a shell account). Many academic institutions also provide a dial up service so that staff with modems can access the Internet from home for the price of a local phone call. Readers with links to academic institutions should contact their local computer services departments for further information.

Unfortunately, at least in Britain, free and easy access to the Internet is not usually available for doctors working outside academia. Even in teaching hospitals, current guidelines limit access to the Internet through JANET to educational and research purposes. However, plans are afoot to provide an NHS-wide network that may feature a one way Internet gateway, allowing NHS staff to access the Internet.

Many companies offering dial up access to the Internet have recently sprung up. These Internet access providers usually charge a connection fee and a monthly subscription fee (typically around $£ 10-20$ in Britain). Most of them have several "points of presence" around the country, which the subscriber can dial to gain unlimited access to the Internet for the price of a local call. Access providers will normally supply the software needed to connect to the Internet, instructions on how to install it, and perhaps also some other introductory material on the Internet. To gain dial up access you will also need a modem; some access providers include this as part of their start up deal.

Services and prices offered by access providers vary widely. When signing up, you should consider not only the costs of the initial connection and monthly charge but also how long you have to sign up for (say, for a three month trial or for a whole year) and the distance to the nearest point of presence. You should also find out what else you are getting (software, guidance on its installation, documentation on using the Internet, dial up and on line user support, support for popular email programs such as Eudora, etc). As commercial provision of Internet services is a fast moving field, the best sources of advice, including up to date lists of providers, are the latest issues of popular Internet magazines such as .net and Internet.

\section{Getting started on the Internet}

Once connected, you can pull yourself up on to the Internet by your own boot straps, using the copious help and range of useful programs that are available

\section{How to read these articles}

These articles have been written in conventional paper journal format and also in an electronic format. Although the paper versions stand as self contained articles, the electronic versions are also intended to act as a starting point for the reader's exploration of the Internet. They contain many additional hypertext references linked to on line resources accessible through the world wide web.

To get to the electronic versions, you will need to beg, steal, or borrow access to a computer that is connected to the Internet and then use a world wide web browser (preferably Netscape) to go to the current issue of the $B M F$ on the $B M F$ s world wide web pages (http://www.bmj.com/bmj/).

Once you have downloaded the web version of any of the articles, you need only click on a citation marker in the text to go to the relevant place in the reference list at the end of the article. From there, you can click on any of the hypertext references to retrieve further information from the Internet on the matters discussed in the text or, in some cases, to download software. If you follow such a link, you need to use your browser's "back" button to get back to the reference list; from there you can click on a "back to text" link to get back to where you were in the text.

free of charge on line; you can access many of these resources through the hypertext references in the on line version of this series (box). Your local computer help desk, medical library staff, and the popular Internet magazines may also provide help.

A wide range of so called client programs allow you to exploit various Internet resources from your microcomputer. Increasingly, these programs provide attractive and intuitive user interfaces that make it very easy to use a particular Internet service. Client programs for most purposes are available for most operating systems (Mac OS, Windows, etc), side stepping arguments over which operating system is best. Programs may be "shareware," which means you are expected to pay a modest fee to the author should you wish to use them after a brief trial period; or they may be completely free of charge, at least to the academic user.

It is not only programs related to the Internet that are free; once the physical links and attendant software and hardware are in place, there is no charge for the movement of information over the Internet (except for the cost of a local call for dial up users). Whether you download a program from London, access a world wide web page from Liverpool, or send an email message to Louisiana, it will all cost you nothing. Who, then, pays for the Internet? A reasonable analogy is with the road system in that the main information highways are usually funded by central government (or by large communications companies in the United States), while the smaller networks and their links to the main highways are usually locally funded (say, by a university). In the United Kingdom the main highway system for academic users, JANET, is funded by the higher education funding councils for England, Scotland, and Wales.

Although there is no charge for moving information over the net, users are bound by an informal code of conduct, often termed "netiquette." For example, netiquette requires that you should not waste the carrying capacity of the net (the "bandwidth") by retrieving files from distant sources, when a more local computer carries the same information. Posting unsolicited advertising to multiple network newsgroups or email recipients (a practice known as "spamming") is also frowned on or even forbidden and is likely to elicit summary justice as disgruntled recipients jam the spammer's mailbox with abusive or 


\section{Internet jargon-a few of the more commonly used terms}

Anonymous FTP: the use of file transfer protocol to obtain freeware or shareware programs or files from publicly accessible Internet sites

Client software: software that runs on your microcomputer, communicates with a server, and thereby allows you to use a particular Internet service

Electronic mail (email): the transmission of text based, letter-like messages between networked computers

File transfer protocol (FTP): a method for moving files from one computer to another over the Internet

Freeware: software that can be obtained and used free of charge

Gopher: a system of interlinked menus that allows access to many Internet resources

Hypertext: a system of electronic footnoting, whereby clicking on highlighted text

Netiquette: the largely informal code of conduct that governs behaviour on the Internet

Network news: a system consisting of several thousand newsgroups that allows discussion of almost every imaginable topic over the Internet

Server: a computer, usually permanently connected to the Internet, that is dedicated to receiving, storing, or dispatching information for a particular Internet service (email, telnet, file transfer protocol, etc)

Shareware: software that is freely distributable but for which you are expected to pay if you wish to use it after a trial period

Shell account: an account on a machine running UNIX that gives text based access to the Internet

$T C P / I P$ : the protocols that govern the movement of information across the Internet

Telnet: a system that allows you to connect to a distant computer (usually running UNIX) and use its services from anywhere on the Internet

UNIX: a text based powerful but unfriendly operating system commonly used on Internet servers

World wide web (WWW): a collection of pages containing text and images that are interconnected by hypertext links that you can explore or exploit simply by clicking with your mouse allows the user to obtain more information about the topic under discussion

time is in the morning, before the east coast of North America wakes up. The net is also a lot quieter at weekends. You are better off doing high bandwidth work (such as downloading large files) at these times.

\section{What is out there?}

Much of the recent interest in the Internet centres on a relatively new feature, the world wide web (the WWW or the web). This provides a user friendly method for accessing, manipulating, and even publishing information on the Internet. However, the web is just one of several ways of exchanging information discussed in this series; others include email, telnet, file transfer protocol, network news, and gopher (box). Although many of these systems have now been woven into the fabric of the web, you will need to understand a little of how they work to get the best out of the web, and they remain important in countries where Internet access is slow or intermittent.

The medical presence on the web is now far too large to be surveyed by one individual. To illustrate the breadth of medical information available, I searched the web while writing this paragraph, arbitrarily taking a relatively rare condition, Recklinghausen's neurofibromatosis, as the subject of the search. The search was completed in two minutes and provided links to seven web pages at four sites. One particularly informative site at the Massachusetts General Hospital provided a description of the condition, complete with magnetic resonance scans, information about clinical services, research, conferences, and self help groups (figure). ${ }^{23}$ A second site, the Hereditary Hearing



Neurofibromatosis on the web Impairment Resource Registry, provided information on neurofibromatosis and hearing loss, ${ }^{24}$ and a third site provided information on Damselfish neurofibromatosis, the only naturally occurring animal model of von Recklinghausen's disease. ${ }^{25}$ That such rich results can be obtained on a fairly obscure subject suggests that whatever your specialty you will find something of interest on the Internet. and the volume of usage at any one time. Access through a modem is likely to be appreciably slower than through a dedicated university link. In my experience, the time of day seems just as important; particularly when accessing American sites. For European users the quietest, and therefore quickest,

junk email. Inappropriate on line behaviour, for lso likely to elicit abusive replies (or "flames")

The speed at which information is transmitted across the Internet varies, depending on the machine

1 sci.med newsgroup: news:sci.med

2 MedWeb: electronic newsletters and journals: http://www.cc.emory.edu/ WHSCL/medweb.ejs.html

3 welcome to HyperJournal: http://www.gold.ac.uk/history/hyperjournal/ hyperj.htm

4 Gainesville VAMC MRI Teaching File: http://www.xray.ufl.edu/ rball teach/mriteach.html

5 EMBL updates, daily, weekly, and cumulative: ftp://ftp.ebi.ac.uk/pub/ databases/embl/new/

6 BioMOO, the biologists' virtual meeting place: http://bioinfo.weizmann.ac.il 70/1s/biomoo

7 Blackwell's bookshops: http://www.blackwell.co.uk/bookshops/

8 Rheingold G. The virtual community. London: Minerva, 1994.

9 Negroponte N. Being digital. London: Hodder and Stoughton, 1995.

10 Stoll C. Silicon snake oil. London: Doubleday, 1995.

11 Herz JC. Surfing on the Internet. London: Abacus, 1995.

12 Faughnan JG, Doukas DJ, Ebell MH, Fox GN. Cruising the information highway: online services and electronic mail for physicians and families. f Fam Pract 1994;39:365-71.

13 Frisse ME, Kelly EA, Metcalfe ES. An Internet primer: resources and responsibilities. Acad Med 1994;69:20-4.

14 McKinney WP, Bunton G. Exploring the medical applications of the internet: a guide for beginning users. Am $\mathcal{F}$ Med Sci 1993;306:141-4.

15 McEnery KW. The Internet, world-wide web, and Mosaic: an overview. AFR Am f Roentgenol 1995;164:469-73.

16 Galvin JR, D'Alessandro MP, Kurihara Y, Erkonen WE, Knutson TA, Lacey DL. Distributing an electronic thoracic imaging teaching file using the Internet, Mosaic, and personal computers. AfR Am $\mathcal{F}$ Roentgenol 1995;164: 475-8.

17 Huntley AC, Conrad SJ. Internet tools in the medical classroom. Med Educ 1994;28:508-12.

18 Kruper JA, Lavenant MG, Maskay MH, Jones TM. Building Internet Annu Symp Comput Appl Med Care 1994;1994:32-6.

19 LaPorte RE, Marler E, Akazawa S, Sauer F, Gamboa C, Shenton C, et al. The death of biomedical journals. $B M 7$ 1995;310:1387-9.

20 Internet domain survey, January 1995: http://www.catalog.com/zone/WWWW/ report.heml

21 Growth of the world wide web: http://www.netgen.com/infoarea/growth.html

22 MIDS Press release: new data on the size of the internet and the matrix: http://www.tic.com/mids/pressbig.html

23 Massachusetts General Hospital neurogenetics home page: http://neuro surgery.mgh.harvard.edu/ngenethp.htm

24 Hereditary Hearing Impairment Resource Registry: http://www.boystown org/hhirr/nurofibr.html

25 NIEHS Marine and Freshwater Biomedical Science Center: http://www. rsmas.miami.edu/groups/niehs.html accessible medical education software using the world wide web. Proc 